\title{
Rural Parents with Urban Children: Social and Economic Implications of Migration for the Rural Elderly in Thailand
}

John Knodel ${ }^{1, *}$ and Chanpen Saengtienchai ${ }^{2}$

${ }^{1}$ Population Studies Center, University of Michigan, PO Box 1248. Ann Arbor, MI 48106-1248, USA

${ }^{2} 1441$ Catalina, Ann Arbor, MI 48103, USA

\section{ABSTRACT}

The present study explores the social and economic consequences of the migration of adult children to urban areas for rural parents in Thailand. Attention is given to the circumstances under which such migration takes place, including the role parents play in the process and the extent to which the implications of migration for the parents are taken into consideration. The analysis relies primarily on open-ended interviews conducted in 2004 with older age parents with migrant children in four purposely selected rural communities that were studied ten years earlier. Our findings suggest that migration of children to urban areas contributes positively to the material well-being of their elderly parents who remain in rural areas. Negative impacts of migration on social support, defined in terms of maintaining contact and visits, have been attenuated by the advent of technological changes in communication and also by improvements in transportation. Phone contact, especially through mobile phones, is now pervasive, in sharp contrast to the situation ten years earlier when it was extremely rare. Much of the change in Thailand in terms of the relationships between rural parents and their geographically dispersed adult children is quite consistent with the concept of the

* Correspondence to: J. Knodel, Population Studies Center, University of Michigan, PO Box 1248. Ann Arbor, MI 481061248, USA. E-mail: jknodel@umich.edu 'modified extended family', a perspective that has become common in discussions regarding elderly parents in industrial and postindustrial societies but rarely applied to the situation of elderly parents in developing country settings. Copyright (c) 2006 John Wiley \& Sons, Ltd.

Keywords: migration; Thailand; older persons; ageing; elderly; modified extended family

\section{INTRODUCTION}

7 he relentless urbanisation taking place throughout Asia, fuelled primarily by the migration of young adults from rural areas, is often portrayed in a negative light among observers concerned with the well-being of rural elderly. The Plan of Action of the United Nations Second World Assembly on Ageing exemplifies this view:

'In many developing countries... the ageing population is marked in rural areas, owing to the exodus of young adults. Older persons may be left behind without traditional family support and even without adequate financial resources.' (United Nations, 2002: paragraph 29)

Such statements are echoed throughout the literature on ageing in developing countries (e.g. Sen, 1994: 10; Jamuna, 1997; United Nations Population Fund, 2002: 19; Kosberg and Garcia, 2004) and fit within a broader argument that 'modernisation' or development, of which urbanisation is a part, undermines the extended 
family including its function as a source of old age support (Aboderin, 2004). Yet so far there is little research to test this assumption (LloydSherlock, 1998).

In contrast, the academic literature on migration, especially as related to the developing world, contains both theoretical arguments and empirical studies that depict the consequences in a much more positive light. Migration is seen as part of a household strategy to diversify risks for families and benefit both migrant and nonmigrant members, including presumably older age parents who typically remain behind in the place of origin (Stark and Bloom, 1985; Stark and Lucas, 1988; Cai, 2003; VanWey, 2004). Most of this literature, however, is urban-based and from the perspective of the migrants. Moreover, even when non-migrant family members are considered, prior studies rarely specifically address impacts on older age parents in the sending areas (Guest, 1998; for exceptions see Khun, 2004; Sando, 1986; Sorensen, 1986; Coles, 2001). Indeed, most migration studies that explicitly consider older people focus instead on the migration of the elderly themselves, especially in connection with retirement and health, and are usually based in economically advanced countries (e.g. Choi, 1996; Silverstein and Angelelli, 1998; Smith, 1998; Burholt, 1999; Cutchin, 2001).

A second body of relevant literature deals with how family relations and structure change as societies evolve from agrarian to industrial and then to post-industrial forms. It also provides both theoretical reasoning and empirical evidence suggesting a more positive view of the impact of migration on parents left behind. Contrary to earlier views that the emergence of modern bureaucratic industrial society leads to the demise of extended family relations, this literature argues that a modified version of the extended family emerges that is adapted to the changed circumstances and the dispersion of its members (Litwak, 1960; Litwak and Kulis, 1987; Smith, 1998). According to this view, advances in technology, especially with respect to transportation and communication, permit family members to maintain close contact and to fulfil many, if not all, of the responsibilities to each other that previously required geographical proximity. So far, this literature has been almost exclusively concerned with the experience in developed countries, especially the US (but see De Vos et al., 2004). Nevertheless, the concept of a 'modified extended family', the modes through which important functions can be fulfilled over geographical distance, and the extent to which such functions are maintained as portrayed in this literature are all interesting to explore in the context of the developing world. In brief, exploring how migration of grown children affects the social and economic well-being of older aged parents is relevant for theoretical concerns involving both migration and the family.

The present study explores the circumstances of migration of rural adult children to urban areas, how rural parents and their situation influence these decisions, and the social and economic consequences for the parents after the children leave. We relied primarily on thematic qualitative analysis of 27 case studies from four rural communities in Thailand. We also drew on limited quantitative information to portray both the local and national situations. Unlike most migration research, we focused on the perspective of the older aged parents who have remained in rural areas, rather than their migrant children. By interviewing rural parents, we can directly learn their views about the full range of social, economic, health and psychological impacts of all their children who have migrated, rather than having to infer a limited range of impacts from reports from a single migrant child in the place of destination.

\section{ANALYTICAL FRAMEWORK}

Arguably, there are both benefits and disadvantages for rural parents as a result of the migration of adult children to urban areas. While their departure reduces availability to provide routine personal care or household help, rural parents may benefit from remittances or derive pride from their child's occupational or social success in the new setting. Moreover, migration including possible return are likely responsive to the changing situation of the parents. Figure 1 provides a framework to guide our exploratory analysis based on the literature, our previous research experience, and observations during fieldwork. The basic theme is that outmigration affects support exchanges between migrant children and their parents which impact the parents' social and economic well-being. Some of the changes will lead to gains and others to losses for each party. Influences that condition support 


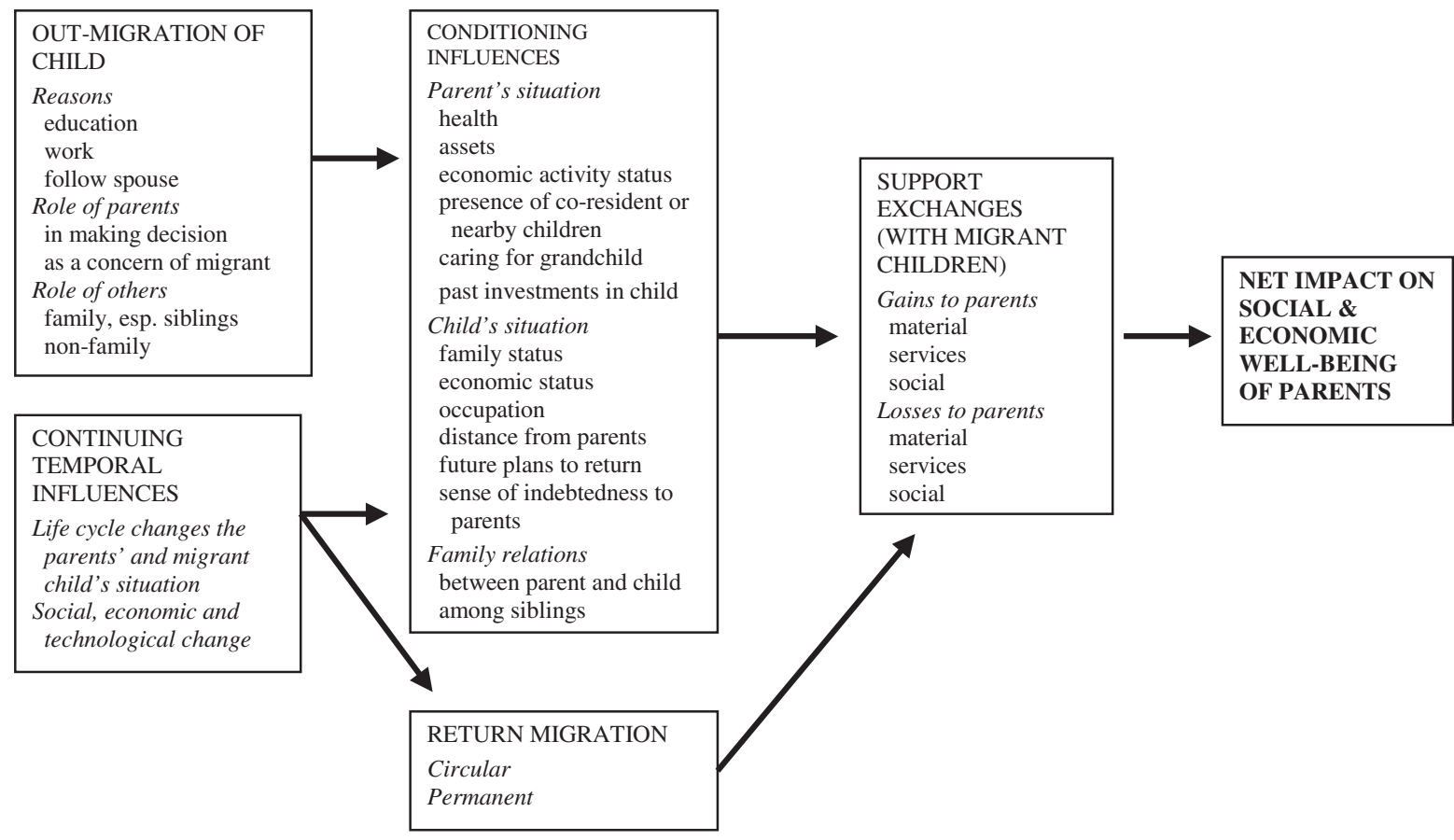

Figure 1. Conceptual framework for exploring the impact of migrant children on the social and economic well-being of 'left behind' parents in rural areas.

exchanges change over time, particularly in response to life cycle changes for both parties (Knodel, Chayovan, and Siriboon, 1996). Thus the net consequences for parents may also shift over time.

Our primary concern is with influences determining support exchanges subsequent to departure of the child but parental influence on the decision to migrate is also of interest. Such influences in either case can relate to the parents' or migrant child's situation. Relationships within the family may also play a role. Conditioning influences may change over the life course of the parents and the migrant children. Also some children may follow a pattern of repeat or circular migration; others may return permanently due to their own and/or their parents' situation. Thus return migration and its consequences are included in the framework although not addressed in the present analysis.

\section{THE THAI SETTING}

Starting in the late 1960s, Thailand experienced a rapid and extensive decline in fertility and substantial increases in life expectancy. Since the current population aged 60 and over established their families when fertility was still high, they still averaged over four living children by 2002. At the same time, their grown children average only two children of their own (Knodel et al., 1992a, 2005). Due mainly to the fertility decline, the Thai population is rapidly ageing and persons aged 60 and older are expected to constitute a quarter of the population by shortly after 2040 (United Nations, 2005).

As in other southeast Asian societies, the Thai family traditionally takes primary responsibility for older members. Widespread norms support filial obligations to parents, and government policy is geared towards reinforcing family responsibility for older persons (Knodel et al., 1995; Ministry of Public Health, 2004). Parents also typically feel a continuing obligation to ensure their children's well-being, and intergenerational exchanges of support and services remain pervasive (Knodel et al., 2000, 2005). Living arrangements are closely intertwined with this system of support exchanges. Most older Thais either live with or very near at least one adult child. Nevertheless, co-residence has declined moderately during the previous two 
decades (Knodel et al., 2005). An overall tendency exists to live with a married daughter rather than a married son, especially in the northeast. This pattern is much weaker in the central region and modestly reversed in Bangkok. ${ }^{1}$ More importantly, Thais are relatively flexible in this matter (Knodel et al., 1992b). Traditionally children inherit equally, although the one who stays with the parents commonly gains the house and, perhaps, an extra share of the land.

During the last several decades, Thailand experienced rapid economic growth that was temporarily, although sharply, interrupted during the economic crisis that occurred in 1997 in the region. Only recently has substantial recovery occurred. These decades of economic expansion were accompanied by a precipitous decline in the importance of agriculture and increasing geographical mobility, especially in the form of labour migration from rural to urban areas (Osaki, 1999; Curran et al., 2003).

\section{RESEARCH DESIGN AND DATA}

The present analysis is based primarily on semistructured open-ended interviews conducted in March and April 2004, in conjunction with a 'census' of persons aged 60 and over in four rural sites (two in Kanchanaburi in the Central region, and two in Surin in the Northeast). We purposely selected the same areas where we had conducted a detailed study of living arrangements exactly ten years earlier, thus permitting comparisons over time (see Knodel and Saengtienchai, 1999). In the original study, Kanchanaburi province was selected for its moderate distance from Bangkok $(100-200 \mathrm{~km})$. There we chose one relatively prosperous site about $20 \mathrm{~km}$ from the provincial town (Central site 1) and another less developed site about $80 \mathrm{~km}$ from the provincial town (Central site 2). Surin was chosen because we wished to include a specific site that had been featured in a 1992 newspaper article on the desertion of the rural elderly resulting from rural out-migration of young adults (Charasdamrong, 1992). We also chose a second site in the same district but substantially further from the main highway. We refer to these as Northeast sites 1 and 2 respectively.

Improvements in road access to all sites during the ten years since the original research were evident, and especially striking for the two Northeast sites where paved roads largely replaced earlier unpaved ones. Transportation links between the sites and provincial centres as well as Bangkok were also improved for all four sites. Also noticeable were improved local government health facilities. In addition, compulsory education increased from six to nine years during the interim, with a consequent expansion of schools. One striking change was increased access to phones, due mainly to the widespread advent of mobile phones. In general, living standards appeared noticeably better than ten years earlier, despite the intervening economic crisis. Still, the two Northeast sites remained poorer and less developed than either Central region site. This is not surprising given how we originally picked the sites and that the Northeast is the poorest region in Thailand (Ministry of Public Health, 2004).

As in our earlier study, in 2004 we collected basic information on living arrangements and migration of adult children as part of a 'census' of all persons aged 60 and over in the four sites (823 elders in 623 households), relying on a combination of existing sources and key informants. We note here that the information appears to be quite reliable, particularly when considering aggregated results. ${ }^{2}$ Table 1 provides an overview of changes in rural living arrangements both nationally and in our sites (taken collectively). The results show that the national decline in coresidence between elderly parents and children is mirrored in our study sites, although overall co-residence is higher. Likewise, the percentage living alone, although still low, increased nationally and in our sites. The share of elders who lived only with a spouse increased. Nevertheless, both nationally and for our local sites, a large majority of older Thais still either had a child in their household or was living very near to one. Finally, the percentage in rural skip-generation households (those with a grandchild and grandparent but no adult child) increased modestly nationally, and the current level in our study sites is similar to that nationally.

\section{Case Study Selection}

We selected older persons (aged 60 and over) from 27 households for semi-structured, openended interviews based on information in the census, consultation with key informants, and preliminary visits. Each case had migrant

Popul. Space Place 13, 193-210 (2007) DOI: $10.1002 / \mathrm{psp}$ 
Table 1. Living arrangements of rural persons aged 60 and over, national and study site results.

\begin{tabular}{|c|c|c|c|c|}
\hline & \multicolumn{2}{|c|}{$\begin{array}{c}\text { National } \\
\text { (for rural } \\
\text { population only) }\end{array}$} & \multicolumn{2}{|c|}{$\begin{array}{l}\text { Four study sites } \\
\text { (combined) }\end{array}$} \\
\hline & 1994 & 2002 & 1994 & 2004 \\
\hline \multicolumn{5}{|l|}{ Percent distribution of living arrangements: } \\
\hline With a child/child-in-law (regardless of others) & 71.8 & 64.2 & $83.8^{\mathrm{a}}$ & 70.5 \\
\hline With others but not children (with or w/o spouse) & 11.7 & $12.9^{\mathrm{b}}$ & 9.4 & 16.7 \\
\hline With spouse only & 13.0 & 16.4 & 4.0 & 7.6 \\
\hline Live alone & 3.5 & 6.5 & 2.9 & 5.1 \\
\hline Total percentage & 100 & 100 & 100 & 100 \\
\hline$\%$ who live with or nearby a child & n.a. & $78.8^{\mathrm{c}}$ & n.a. & 83.9 \\
\hline$\%$ in skip-generation household ${ }^{\mathrm{d}}$ & 8.9 & 10.3 & n.a. & 11.2 \\
\hline
\end{tabular}

Source: National estimates are based on original tabulations from the 1994 and 2002 Surveys of Elderly in Thailand conducted by the National Statistical Office; study site estimates are from our census of older persons in the four sites (see text).

${ }^{a}$ Excludes the elderly who live with a child-in-law but not a child.

${ }^{\mathrm{b}}$ Includes a small number of indeterminate cases.

${ }^{\mathrm{c}}$ Defined as co-residing with or seeing a child at least several times a week.

${ }^{\mathrm{d}}$ Defined as living with at least one grandchild but no child or child-in-law. In the case of the study sites, only grandchildren aged under 18 are considered.

Table 2. Comparison of provincial research sites and cases interviewed in detail, by location of nearest child and other selected indicators.

\begin{tabular}{|c|c|c|c|c|}
\hline & \multicolumn{3}{|c|}{ All persons 60 and over in study sites } & \multirow{2}{*}{$\begin{array}{c}\text { Cases } \\
\text { interviewed } \\
\text { in detail }^{\mathrm{a}}\end{array}$} \\
\hline & $\begin{array}{l}\text { Kanchanaburi } \\
\text { (Central region) }\end{array}$ & $\begin{array}{c}\text { Surin } \\
\text { (Northeast) }\end{array}$ & $\begin{array}{c}\text { Total } \\
\text { sample }\end{array}$ & \\
\hline Average age of elderly person & 69.4 & 69.7 & 69.5 & 67.5 \\
\hline \multicolumn{5}{|l|}{ Nearest child (\% distribution) } \\
\hline Co-resident in parental household ${ }^{\mathrm{b}}$ & 74.8 & 63.9 & 70.5 & 47.7 \\
\hline Nearby parental household & 13.7 & 14.3 & 14.0 & 9.1 \\
\hline In same subdistrict (tambol) & 1.8 & 4.0 & 2.7 & 11.4 \\
\hline Elsewhere & 5.2 & 9.0 & 6.7 & 31.8 \\
\hline Childless & 4.6 & 8.7 & 6.2 & 0.0 \\
\hline Total percentage & 100 & 100 & 100 & 100 \\
\hline$\%$ in a skip-generation household ${ }^{c}$ & 9.1 & 14.3 & 11.2 & 22.7 \\
\hline$\%$ with a migrant child ${ }^{\mathrm{d}}$ & 73.4 & 78.8 & 75.5 & 100.0 \\
\hline$\%$ with a migrant child in Bangkok area & 28.8 & 53.3 & 38.3 & 72.7 \\
\hline$\%$ with a returned migrant child & 21.0 & 17.8 & 19.7 & 27.3 \\
\hline
\end{tabular}

Source: Our census of older persons in the four sites (see text).

${ }^{\text {a }}$ Based on 44 elders in 27 households.

${ }^{\mathrm{b}}$ Includes a small number of cases in which a child-in-law but not a child is co-resident.

${ }^{c}$ Defined as living with at least one grandchild aged under 18 but no child or child-in-law.

${ }^{\mathrm{d}}$ Migrant child is defined as living anywhere outside the subdistrict of the parent.

children (i.e. living outside the parents' subdistrict). We disproportionately chose parents with a migrant child in Bangkok or the surrounding area (a prime destination of rural to urban migrants), and parents who did not live with any of their children. Overall, the 27 cases involved 44 elderly parents. ${ }^{3}$ In five cases, we were also able to talk with an adult child who had previously migrated but had returned or who was currently visiting. ${ }^{4}$ As Table 2 shows, based on the 'census' of older persons, there is little difference between the two sets of 
provincial sites in the average age of older persons or in the percentage of elders who have a returned migrant child present in their locality. However, co-residence is less common, and both skip-generation households and childless elders are more common, in the Northeast than the Central sites. Northeast site elders are also substantially more likely to have a migrant child, especially one in Bangkok.

Table 2 also indicates the characteristics of the cases chosen for interview. They were somewhat younger than the overall elderly population in the study sites. Differences in the location of children stem from selection of cases based on the substantive concerns of our research. All have a migrant child and nearly three-quarters have one in the Bangkok area. They are far less likely to coreside with a child and more likely to live with a grandchild whose parent is absent. Almost a third had no child within their own subdistrict. Finally, they are more likely to have a returned migrant child living with or near them. Although we did select cases on their socioeconomic level, they clearly covered a wide spectrum from the desperately poor to relatively comfortable, within the rural context. Given the deliberate choice of one site which was featured in a newspaper that focused on lack of support for elderly parents, and our disproportionate selection of parents who did not co-reside with an adult child, our research design should increase the chances that our results would capture, and perhaps be skewed towards, negative consequences of migration for 'left-behind' parents. ${ }^{5}$

\section{FINDINGS FROM CASE STUDIES}

Migration histories can be quite complex, often involving multiple moves. Most migrant children, however, had not returned other than for temporary visits, even if they had made several moves. Although some may eventually return, many others are likely to live away permanently. Thus, the initial departure from the parental household to migrate elsewhere, although it typically occurs in a context of uncertain intentions, frequently has significant implications for the parents' future living arrangements. Hence, we start our analysis by examining these initial departures. We then turn to the impact on social support and finally, to economic support.

\section{Departing Parental Households}

Migrant children typically left as adolescents or young adults, often following completion of compulsory schooling and a period with parents. Most who migrated were at least aged 15, but only a third were older than 20 at the time. Thus, not surprisingly, the large majority were still single. The Bangkok area was the initial destination for over half of the more than 90 children reported to have migrated, and many who initially went elsewhere eventually spent time in Bangkok. In this section we examine reasons for migration, the role of parents and others in the process, and the saliency of the implications of migration for parents' well-being.

\section{Reasons for Migration}

Work, education and marriage constitute the three major reasons for leaving the parental household and moving elsewhere, with work being by far the most common. In general, parents considered moves precipitated by marriage or to follow a spouse as normal and expected, even when the child would be a considerable distance away. Marriage can also anchor children to the home community. One widow noted that had her son, who had returned from Bangkok, not married a local woman, he would be back in Bangkok just like his brother.

Migrating elsewhere to continue education accounted for about a quarter of the migrant children reported by our case study parents in the Central region sites, but for very few in the Northeast sites. This sharp difference probably reflects the generally more impoverished settings of the Northeast sites. In a few cases, young children joined relatives or siblings elsewhere, usually Bangkok, to study. Far more commonly, children went to get vocational or tertiary training. Examples include children going to attend nursing, technical and commercial schools.

By far the most common reason for migrating, especially to urban destinations, was for employment. Appropriate jobs are rarely available in the home community for those who have received tertiary or specialised vocational education. Thus, many who had left to study simply remained away. Others returned temporarily while seeking appropriate work elsewhere. Similarly, when a child commuted to vocational or higher educational institutions from home (as 
some in Central site 1 near the provincial town did), most still needed to move elsewhere to find a suitable job. One parent whose daughter had received a vocational degree and then left for Bangkok stated:

'She graduated and simply should find a job. If not, she had to work on our rice fields, which are very small, and the income might have been less than the expenses. It's good that she's gone for work.' [married father, Central 1, $1 / 96]$

In many cases where children pursued education and then left to work elsewhere, parents were proud that the children were able to find appropriate employment and advance their careers, even if they had to leave home to do so.

A very different and far more common link between education, migration and finding a job arose from the need to make a living after finishing compulsory education. In these cases, both parents and children typically viewed migration as a necessity arising from the lack of opportunities in the home locality, especially if the parents had limited or no agricultural land. In addition, many parents and children viewed agricultural work in a negative light.

'If he stayed here, he wouldn't get anywhere. There was no work for him. Going there, he could earn a bit more each day. Here, there is only planting sugar cane. It is hot and hard work. Working as he did in Bangkok was better.' [married father, Central 2, 61/126]

'I asked her to go, for being here, she had to be hired to work in the hot field exposed to the sun, like me and her dad working so hard. In Bangkok, she wouldn't work outdoors in the sun.' [married mother, Central 2, 107/96]

Even low-level jobs in Bangkok, such as factory, restaurant or domestic work, were viewed positively and clearly preferably to being underemployed or inactive in the home village by poorer parents whose children finished only the compulsory primary school.

\section{The Role of Parents and Others}

Decisions resulting in children leaving for urban areas or other distant places typically involved not just parents and children themselves, but others as well. As previous research indicates, social networks play a vital part in the migration of children. The roles of relatives and siblings were particularly prominent, although friends or other acquaintances could also be key influences. That a child would join a sibling or a relative often helped to allay parents' concerns for their child's safety and well-being, particularly in an urban setting. Parents tended to be more apprehensive when the child joined friends or, in some instances, when the child did not even consult the parents before leaving. Quite commonly, a relative or sibling arranged a job for the newcomer and provided accommodation, at least initially. Even if the child were to leave to continue education, assistance from relatives or siblings was not unusual.

'My sons and daughters moved to work in Bangkok because of their eldest brother. They can earn more money in Bangkok because there is no occupation for them here. When one goes there and the living is better, the others follow them.' [married father, Northeast 1, 584/157]

Other than paying for education that channelled children to particular types of jobs not available in the local community, parents rarely reported that they directly financed costs associated with the initial move. This is unsurprising in the light of poverty in the study sites and the fact that many children, especially in the Northeast sites, left due to their parents' economic hardship. Moreover, the costs involved were typically modest since transportation is inexpensive and migrant children often know someone in the destination who could provide shelter.

More surprising is that parents rarely mentioned that they helped migrant children to find a job. Still, given that relatives or siblings were often involved in providing or arranging jobs or accommodation, parents probably played some intermediary role in making the arrangements. If a relative or sibling of the migrant-to-be played an instrumental role in arrangements, it is likely they would at least consult the parents in advance, especially if the move involved an adolescent child leaving home. In some instances, parents may even have been the ones to initiate the arrangement. However, since we did not specifically probe this issue in the interviews, we can only infer the parents' role in helping with arrangements. 
Parents usually were in agreement that the child could migrate, and in the large majority of instances gave their consent. When the move was associated with marriage, parents typically accepted this as normatively appropriate. When the child left home for education, parents were often instrumental in the move. When the child left to find work, the child often appears to have come up with the idea but also to have requested parents' consent. In a few instances, a child went away, typically with friends, either without telling the parents or against their will. In these cases, parent-child relations were probably strained even before the departure, and sometimes remained so afterwards. However, in the few cases of this type we encountered, the migrant child eventually resumed contact with their parents.

While parents usually consented to their child's departure, some were clearly ambivalent, mainly out of apprehension about the child's own welfare. This appears to be more for daughters than sons. In several cases, the father either accompanied or visited a daughter soon after migration to allay worries about her situation. Nevertheless, parents often saw little alternative to the child leaving, given the limited opportunities to make a living locally. Moreover, given how common such migration was in the communities, departures were an expected life course event for most families.

\section{Saliency of Implications for Parents}

Given the focus of our research, we are particularly interested in the saliency of parents' welfare as a concern at the initial departure from home. Although the impact on the migrant children themselves is beyond the scope of the present study, it is important to recognise that for parents, the migrant child's well-being appears to have been a far more salient consideration than their own well-being, especially when children left to find work in an urban area or to gain further education.

Interviewer: 'When she was about to leave, did you think with whom you would live? Did you think of yourself in this respect?'

Father: 'I was hardly concerned about myself. Since I have some land and work growing rice. I only worried about my daughter. She was young at that time; she might not have thought much about it. There was no telephone those days. If I missed her or was worried, I had to go to her.' [married father, Central 1, 1/51-2]

Long-term implications of migration for parent's welfare in old age were rarely considered by either migrant children or their parents at the time of initial departure from home. This likely derives from several key influences. Firstly, given the young age at which most children first left, the initial departure typically occurred when the parents themselves were still economically active and physically well. Thus, parents often did not see a need for the child to remain in the locality to assist them. Secondly, given that today's elderly typically have many children, when one departed there would often still be others at home or nearby. In addition, when children migrated, there was often genuine uncertainty about the permanency of the move, and some parents held expectations or at least hope that one or more of their children would later return. Since most Thai elderly have multiple children, only the departure of the last child would result in the parents living without a child. Yet, interestingly, in the five cases we interviewed in which all the children had migrated, little evidence emerged that the last child's departure was of particular concern, although in part this could reflect insufficient probing.

To the extent that the implications for the parents' well-being were considered by either party, it was usually from a more immediate than a long-term perspective. The inability of some parents to support their young adult children adequately contributed to this. Some with little or no land saw the departure of their children as relieving economic strain within their household.

Interviewer: 'Having your children leave home for here and there, sometimes coming back and then leaving again, makes you concerned, doesn't it?'

Father: 'No, not at all. Only that they have a job and money without depending financially on us. Their living away, it is fine for us. They don't leave for good; they come home once every few months or on festive holidays, such as Songkran (Thai New Year) or Lent.' [married father, Central 2, 50/160-1]

Far more common, particularly in the Northeast sites, was the anticipation of the support that 
migrant children would be able to provide to parents soon after the move to relieve current economic hardship. The idea that migration could help to support parents could be initiated by either the child or the parent.

'She said she didn't like living in the country, but preferred living in Bangkok. She consulted with me and told me that if she could earn money, she would send me some. So I let her go as she wished, she was going for work, not for fun. Leaving to work, she could afford to feed herself and the family. Staying here, she had nothing to do.' [widowed mother, Central $1,214 / 46-47]$

Not all parents, however, expected meaningful material support. Several explicitly denied this, making clear that their primary consideration was that the move would benefit their child.

\section{Migration and Social Support}

Interaction with grown-up children, including face-to-face contact, is a valued and important source of social and emotional support for most older aged parents. Since the migration of children clearly reduces opportunities for face-toface interactions, it potentially undermines such support. However, geographical separation does not preclude maintaining contact, and periodic face-to-face contact is possible through visits. In this section, we examine how contact between parents and migrant children is maintained, as well as the nature and frequency of visits in either direction.

\section{Maintaining Contact While Away}

Not long ago, maintaining contact, especially on a regular or frequent basis, was difficult for both rural parents and their children living in distant places in Thailand. If parents urgently needed to reach migrant children, the main option was through telegrams. This required both access to a post office and knowing an address where the child could be reached. The latter could pose a serious problem if the child moved frequently or lived in temporary housing typical for those in construction work, a common occupation of migrant children from poorer families. Letters could be used for less urgent matters, but took several days to arrive, required literacy, and took an effort to compose. Messages could be passed by intermediaries who travelled back and forth, but this depended on chance opportunities.

In the last few years, the widespread availability of mobile phones has literally revolutionised the ability of rural parents and their children living elsewhere, especially in urban areas, to contact each other. When we conducted fieldwork in the four sites in 1994, telephones were almost nonexistent in the villages. Even today, private land-line telephones are extremely rare. Public pay telephone booths, although now common in villages, are often out of order and are only convenient for calling out but not for receiving calls. In contrast, mobile phones are both convenient and increasingly common. The vast majority of parents reported that they have had at least occasional and, in numerous cases, fairly frequent phone contact with migrant children through mobile phones. Quite a few had a mobile phone of their own, typically provided by a migrant child. Sometimes a co-resident child or grandchild would have a mobile phone. Even elders with no mobile phone in the household usually had access through a neighbour or nearby relative. In addition, many migrant children had their own mobile phones, and those who did not knew someone who did. Only in one out of the 27 cases we had interviewed was there no contact with any child by telephone. In other cases, telephone contact was sometimes reserved for urgent matters, and hence infrequent. In addition to greatly facilitating contact for social and emotional reasons, mobile phones also serve practical purposes for both parents and children.

Wife: 'In the past, we had to write them letters, which took long to reach their hands. It's better now via phone.'

Husband: 'Only a ring. We don't have one, but all our children do. It has become much more convenient in the past two years since mobile phones are used everywhere. They were expensive before... but I've heard now one only costs (a small amount).' [married father and mother, Central 2, 50/191-2]

Observer: 'What do you do, when you want to get in touch with the children in Bangkok?' Husband: 'I call them using a mobile phone [of the co-resident son]. We often call each other ... They call me to ask about us if I failed to contact them for too long, or when they have business and want to ask me to do something 
for them, such as dealing with the district office about the household registration and so forth.' Wife: 'If our son isn't at home, they call that house [the wife's brother's house next door]. And my sister runs to us bringing the telephone... Sometimes, when the elder brother misses a call, the younger sister calls back asking whether mom and dad want anything. Dad mentions that he feels like eating things such as herbs, a ground lizard, or a bullfrog and she then manages to bring him some. When she gets a ground lizard, she'll bring it here at once.' [married father and mother, Central 2, 61/162-171]

One circumstance that clearly served to increase the likelihood of frequent calls was the presence of the migrant child's own children in the household. Migrant sons or daughters would call to check up on and speak to their children if the children were old enough, but at the same time they would also talk to their own parents. In some cases, the grandchildren had even been given their own telephones. Mobile phones also make it easier for migrant children to consult with each other about their parents' welfare and health, and to coordinate visits, joint outings or provision of material support. In at least three interviews, the parents specifically mentioned how their children would phone each other when they were ill.

'If I get sick, I'll call her. Then, she will phone to tell her siblings. Or when I run short of money, I also tell her. She'll call to tell her brothers again. When I get sick, all our children know that we don't have money, so they help us. In normal condition, we sometimes have financial trouble, so we call to tell her.' [married mother, Northeast 1, 532/75]

Focus group research at the start of the 1990s revealed that healthcare concerns, including getting to a doctor or hospital, and personal care when ill or bedridden were the needs most salient to many elderly participants and constituted an important reason for wanting children either to co-reside or live nearby (Knodel et al., 1995). The widespread availability of mobile phones seems to have noticeably reduced this concern. Significantly, participants from four of the five cases with no nearby adult children specifically mentioned that they could call a child if they became sick. In the remaining case, a daughter called twice a week; so presumably if a healthcare need arose, they could quickly let her know.

\section{Visits}

Visiting constitutes an important means of contact between rural parents and their migrant children, especially given the opportunity for face-to-face interaction. It is extremely rare for a parent not to see children who had moved away on at least an occasional basis, and even rarer for them to lose contact completely with children once they migrate. Although visits can go in either direction, migrant children make return visits to their home village far more often than parents make visits to migrant children.

Children to parents: In Thailand, there is a strong tradition of adult children who are away returning to pay respects to their parents on Songkran, the three-day Thai New Year celebrations in April, and many do so. Other holidays are also occasions for visits, especially if they span several days. Special events such as weddings, funerals, ordination ceremonies or organised merit-making trips to the home village temple (Katin or $\mathrm{Pha} \mathrm{Pa}$ ) can also prompt visits back to the village. Thus, parents see almost all migrant children at least once a year and in many cases see at least some of their migrant children more often, as documented in several national surveys (Chayovan and Knodel, 1997; Knodel et al., 2005). None of the 27 cases of parents we had interviewed reported not seeing a migrant child at least once a year, and only six reported having a migrant child whom they saw less than once a year (including one whose daughter lived abroad but called often).

Numerous factors influence how frequently urban-based children visit rural parents. Distance is one. Frequent visits were more common for the parents in the Central sites than in the Northeast, reflecting the shorter distances involved and the relative ease of transportation from Bangkok. Another is the presence of grandchildren who were sons or daughters of the migrant child, especially migrant daughters, in the household. Regular and frequent visits were often associated with visiting a child in the care of the rural grandparents. In contrast, migrant children who were raising their family in the new 
location were less likely to visit parents. A number of parents accept this as being understandable. Compared with unmarried migrants, those who were married were more firmly rooted in their own new community and typically had parents-in-law to consider for visits.

The type of work and distance to travel could also influence the children's ability to visit, especially when the travelling time was long, as in the case of Northeast migrants who work in the Bangkok area. Self-employed migrants, such as taxi drivers or street vendors, are better able to take time off than regular employees. Parents often cited the inability of a child to leave their work as a reason why a child did not visit often. In some cases this may have been more a rationalisation to excuse a negligent child, but in others it was likely to be a genuine consideration.

'It is not easy for him to come. His work doesn't allow him long leave. He can't be absent more than the permitted amount. At the time his dad died, he came to his dad as he was hospitalised, but had to return while his dad was still suffering.' [widowed mother, Central $1,5 / 62]$

Financial considerations could influence the ability to take time off work and to afford a trip back home, especially since many migrant children feel a sense of obligation to provide at least some token money or gifts to their parents on the occasion. In a few cases, strained relationships between parents or co-resident siblings and a migrant child kept visits infrequent. More commonly, however, the opposite was true, with siblings coming together to visit parents or getting together among themselves as well.

For some parents and migrant children, being able to talk frequently on the telephone can substitute for visits or compensate for infrequent visits, especially when the child lives a substantial distance from home. This is exemplified in the following exchanges.

Interviewer: 'What about your son ... ? Does he come here often?'

Mother: 'Not so often. He is busy. He has to work and pick up his children. Their school is very far... But he has to come during the festivals.'

Father: 'He calls us, too.'
Mother: 'He calls us regularly ... I said to him, "Son, have you seen the ad on TV where the mother calls her son and the son asks are you sick and she answers no I just want to hear your voice"? So he calls us saying, "hello, how are you, and how about dad?"' [married mother, Central 1, 337/228]

A variety of reasons prompt migrant children to visit parents in their home community. Often the emotional need to see parents and a sense of obligation to provide social support underlie visits. But these are often mixed with other motivations and circumstances, such as returning to vote or carrying out business at the district office. Perhaps most importantly, visits by children are intricately linked to the provision of material support to parents. Although money can be and often is sent to parents through the post office or other means, a common pattern is to bring the money personally whenever possible. Visits for this purpose can be frequent and regular or just occasional. A reasonable share of cases where visits were frequent and regular were associated with bringing money to parents, especially parents who were caring for the migrant's own child. In many other cases, however, money given during visits had more symbolic value.

Parents to children: Visits by parents to their migrant children were considerably less common and were often associated with some special purpose. Many parents had migrant children whom they had never visited and several did not even know their children's addresses. One motivation to visit, especially daughters soon after they have left home, was concern about the child's welfare. Health problems also led parents to spend time with migrant children. Several had gone for operations or treatment at hospitals close to where their children were living and had stayed on afterwards to convalesce. Others simply went to be cared for by their children when in poor health. In two cases, a mother went to help to care temporarily for a grandchild. Although visits by parents to children mainly for social reasons took place, they were far less frequent than social visits by migrant children to parents.

Mother: 'Not so long after she had gone [to Bangkok], she wrote us a letter telling us there 
was no need to worry, she could live there. After she had gone for 4-5 months, Dad visited her.'

Father: 'I went alone. Mom stayed home. She explained in her letter how to go, where to catch a bus and get off, and where to change the bus ... I went to see how she lived. It was not too bad.'

Mother: 'I've been there once for a month when I had an eye operation. I stayed with her and in the hospital, too. I don't like Bangkok. I have no friends there. I couldn't go out anywhere and had to sit in the house all the time.' [married couple, Northeast 1, 615/62]

Visits by parents are not so common for several reasons. It is typically far easier for a migrant child to return than for older aged rural parents to travel to an unfamiliar urban area. Several parents said that travelling long distances would be physically difficult for them. Others mentioned a need to stay at home to care for grandchildren, or worried about leaving their house, fields or animals unattended. A number mentioned that they would be out of place in a city, not knowing what to do or how to get around on their own. Other deterrents were cramped space in the child's dwelling and, related to this, concerns about inconveniencing their child or strained relations with their child's spouse.

Daughter: 'Both Dad and Mom have been to Bangkok. They couldn't be there more than a week.'

Father: 'There, I could just sit in the house.'

Daughter: 'Yes, they could only sit still. Walking anywhere, they were afraid of motor vehicles and getting lost. Their children had to go working ... They moaned to go home.'

Father: 'I missed my cattle and my field.' [Northeast 1, 596/147]

\section{Migration and Economic Support}

Extensive survey data document the importance of adult children in Thailand for providing financial and material support for older aged parents. According to a 2002 national survey, $77 \%$ of all Thais over 60 reported receiving such support from children during the previous year, and $71 \%$ reported that either a child or child-in-law were their main source of income (Knodel et al., 2005). These results refer to the combined support from all children, whether or not any were migrants. A 1995 national survey of Thais aged 50 and over indicated that among rural parents with at least one adult child living in a different province (and thus a likely migrant), $78 \%$ received some money in the prior year and $62 \%$ received at least 1000 Baht (US $\$ 40$ at that time) from one or more of these children. ${ }^{6}$ In addition, $78 \%$ received food or gifts from these children in the previous year. Some older aged parents had also provided economic assistance to their migrant children. According to the 1995 survey, almost a quarter gave some money to at least one child living in a different province, almost a fifth gave at least 1000 Baht, and just over a third gave food or other gifts. In this section, we explore both support provided to and given by parents.

\section{Support to Parents}

Among our case studies, economic support from migrant children came mainly in the form of money and gifts. Not all migrant children provided such support, although over four-fifths gave at least some money. All of the parents interviewed had received some monetary support from at least one of their migrant children. Also, parents commonly received gifts, mainly in the form of food.

Financial support: Monetary support from migrant children varied considerably in amount and frequency. Most common were occasional gifts of money associated with visits as described above. The amount provided on such occasions was often modest and sometimes only of token value. In other cases, the amounts were moderate to substantial. Irregular contributions, independent of visits, were also received. In other cases, children who gave money during infrequent visits also occasionally sent money by other means. Another common pattern which was typically more significant in terms of the impact on the parents' economic situation were regular remittances intended for the parents' daily living expenses and, in some cases, to permit parents to save for some major expense. About half of our case studies were receiving such regular support at the time of the interviews and a few others had done so in the past. Such regular support could be brought personally by the child or sent as money orders. 
'The youngest daughter supports us with 10,000 Baht once every two months. She lives in Bangkok, she gives us regularly... She doesn't send by post for fear that it might get lost ... She comes to us every two months with money for us. But she never stays overnight. Comes on Sunday, returns the same day.' [married father, Central 2, 143/86]

The amounts of regular remittances varied considerably and in a number of instances were associated with grandchild care, although sometimes the amounts provided were sufficient to cover childcare and also to help support the parents, while in others it was not. In five cases, the grandparents bore much of the grandchild care expenses themselves and in two of these it seemed to be a burden. Financial support could also be targeted for special purposes such as healthcare. In cases of chronic illnesses, healthcare support could be routine, but more commonly it was associated with urgent situations. In a few cases, children had health insurance that also covered their parents. Support from some children also included improving the parents' house, building a new one or buying land for the parents. These amounts would typically be substantial and might come from irregular but large payments or from savings by the parents from more regular but generous remittances, perhaps with an understanding between parents and children that this would be the case.

Interviewer: 'How did the children's moving away affect your lives?'

Father: 'My daughters sent us money to buy land (for rice fields) . . . the sons paid for building the house... Sometimes the elder and sometimes the younger. The other daughter also paid for a time... That's why we finally have a big house and cattle. Our children helped us and contributed bit by bit... Thus, I can meet the expenses thanks to my children.' [married father, Northeast 2, 582/146]

It was not unusual for parents to receive different forms of support from different children or for the form to alter with circumstances related either to the needs of the parents (such as changes in health or the entrance or exit of a grandchild from the household) or the ability of the migrant child to provide support (such as loss of a job or starting their own families).
'My third daughter is a nurse. She doesn't like buying a little of this or that. When she gives us, she gives something big or a large sum of money, such as a mobile phone, a TV, a table, a swing. The eldest daughter looks after our miscellaneous things, such as food, clothes, monthly telephone bill, or small pocket money.' [married mother, Central 1, 263/73]

Parents also mentioned that some migrant children either never gave them money or only gave trivial amounts. Some parents even cited instances where they had to pay for the return bus fare at the end of a child's visit. While in some cases the lack of support clearly disappointed the parents, in others the parents stressed that the children's own difficult situation prevented giving more and thus was understandable. In at least two cases, parents who were already financially comfortable discouraged children from giving other than token support, believing that their children could better use the money themselves.

Non-monetary support: Virtually every case we interviewed reported receiving some nonmonetary support from their migrant children, if gifts of food brought along on visits are counted. Children sometimes brought special and expensive types of food that they knew were their parents' favorite or that symbolised a special occasion. For obvious practical reasons, however, only non-migrant children who co-resided or lived nearby regularly provided food to older aged parents. Less frequently, clothing was brought in connection with visits. As with food brought by migrant children, such gifts rarely had great economic value.

Of greater economic significance were gifts of household appliances and, as discussed above, mobile phones. In at least half of the cases we had interviewed, parents received appliances from migrant children. These included both small, inexpensive items such as a fan, thermos, electric pot or radio, as well as far more costly items. Among the latter, televisions and refrigerators were most common but also in several cases, furniture and in at least one case each, a washing machine, stereo equipment, an air conditioner, exercise equipment, carpentry tools, and a water pump. In two cases, migrant children gave their parents a motorcycle, and in one case a car. Several parents reported support in the form of 
labour, most commonly involving a migrant child who would return to assist at particular times of the agricultural cycle when intense labour was needed.

\section{Support from Parents}

Although less common, economic support also flowed from parents to migrant children; often it was of a non-monetary nature in the form of village products or, most importantly, childcare services.

Financial support: Aside from paying for children going elsewhere to study, parents rarely financed the living expenses of migrant children. However, in at least a quarter of the cases interviewed, parents provided substantial financial help associated with special circumstances or purposes. These included paying a large debt incurred by a daughter and funeral expenses for her spouse; financing a son's travel to Taiwan to work; paying a bribe to exempt a son from military service; taking out a loan to pay their grandchildren's educational fees; financing a daughter's apprenticeship training in Bangkok and the establishment of a beauty shop when she returned; buying land or building a house in the village to prepare for the return of migrant children; and helping to pay for a son's wedding in Bangkok. In several cases, parents mortgaged or sold land and cattle to cover these expenses. Such financial assistance was mainly limited to parents who had savings or assets to cover them, and thus did not involve those who were particularly poor.

Non-monetary support: Two other types of support which rural parents provided were not limited to those of any particular socio-economic situation: the provision of village products and childcare services. The former, especially rice, was sometimes given to migrant children when they came for a visit or when parents visited then. The quantity given ranged from only token to substantial amounts. Undoubtedly, the most important type of non-monetary support provided to migrant children was taking care of grandchildren who stayed with them in the village, and less frequently, providing temporary childcare in the city. Clearly these services have significant economic value for the migrant children, permitting them to work outside the home without hiring someone to mind their children. Almost half of the cases we had interviewed were then caring for grandchildren whose parents had migrated, while two others had done so in the past. Although in most cases the migrants helped to pay the costs involved, this would typically be less than what the arrangements would cost in the city; also, knowing that their children were in their grandparents' rather than someone else's care was likely to be psychologically comforting for the migrants (Richter, 1996).

\section{DISCUSSION}

Assessing the social and economic impacts of the urban migration of adult children on parents who have remained in the village, based primarily on qualitative data, necessarily requires subjective judgments. However, we believe there is sufficient information in all but one of our case studies to at least broadly characterise impacts on material well-being with reasonable confidence. Measuring social well-being is less straightforward. In spite of this, our interviews provide a basis for some relevant general observations on this also.

\section{Impacts on Economic Well-being}

Our findings suggest that for many, probably most, rural Thai elderly parents, the migration of children to urban areas contributes positively to their material well-being. Only three cases we had interviewed appeared to have experienced a net economic loss as a result of their children's migration. This is particularly striking since, as noted above, our selection of sites and cases should have increased chances of encountering negative impacts. Moreover, in two of these cases, the negative economic consequences seemed as much linked to problematic relationships within the family as to migration itself. Also noteworthy is that the three cases were not among those who were particularly poor.

At the other extreme, parents in four of our cases clearly benefited a great deal from children migrating to urban areas. These include the two most economically well-off couples of those interviewed. Both started from very humble beginnings and all their children had migrated. Their children got decent jobs elsewhere and were willing, indeed eager, to support their parents, with the result that the parents are now 
materially comfortable. Both couples were also quite content with the social support they received through regular visits and phone calls.

Among the remaining cases, over half apparently benefited financially from their children's migration, although some only modestly. For the rest, the migration had had little economic impact. Most of these latter cases had been quite poor at the time the children departed, and had remained so. Their migrant children had little education and hence were not positioned to get well-paid urban jobs. Thus, for some poor parents with little land or other assets and no savings, migration of children may not bring tangible benefits, but it is also unlikely to cause additional economic hardship for the parents.

Previous research in Taiwan found that older aged rural parents, in the absence of their children, were unable to cultivate their land themselves and either hired labourers or rented the land to someone else (Sando, 1986). Several similar situations occurred in our study sites. However, they did not usually present a major problem given that the parents affected typically had only limited land to cultivate, and in two cases migrant children had provided money to pay for the hired labour.

Many parents explicitly said they had benefited from the financial support provided by their migrant children. In seven cases, migrant children had helped to pay for a new house or for major improvements to the current one, and in two they had bought land for the parents, indicating that the economic impact could be substantial. Several parents mentioned that migrant children were able to support or assist their siblings' education. Also, because migration enabled children to support themselves, some parents felt relieved of what could otherwise be a serious burden for them. Indeed, most parents believed that migration to cities provided their children with better opportunities to earn a living independent of any benefits that they, as parents, might gain. Just knowing that children had employment in urban areas provided parents with an important psychological benefit in addition to any economic ones.

\section{Impacts on Social Well-being}

Indicators of parents' social well-being are less observable than those for material well-being. We

Copyright (C) 2006 John Wiley \& Sons, Ltd. focused on maintaining contact and visiting as key aspects of social support. Some parents had conflicted feelings about their children living away. While they would like to have them nearby for company, they also understood that their children gained greater opportunities for earning by migrating. Also, the social impact created by the absence of those who had left was moderated by the fact that most parents still had at least one child co-residing or living nearby.

Clearly, recent technological changes in communications and improvements in transportation have attenuated the negative impacts of migration on social support; the advent of relatively inexpensive mobile phones in particular has made contact between migrant children and their rural parents far easier than just a few years ago. Telephone contact is now pervasive. The ability to contact each other at short notice helps allay the concerns of both parents and migrant children about marshalling each other's help in a time of crisis, particularly when a parent falls ill. More generally, telephone contact can provide an important source of emotional support, as a parent whose children had all moved away clearly recognised:

'Although our children are far away from us now, we don't feel such distances thanks for constant contact by telephone. This really makes us feel as though they were near us. Telephone technology nowadays is quite advanced.' [married mother, Central 1, 263/120]

Better means of transportation and a constantly improving road system also facilitate visits between parents and their migrant children. Although we lack systematic evidence to document change, we suspect that visiting increased in our four sites, given the level of improvement of roads and long-distance bus travel recently.

\section{CONCLUSIONS}

Contrary to claims embodied in much of the discourse about the rural elderly in the developing world, extensive rural to urban migration of adult children has not led to the widespread desertion of 'left-behind' elderly parents in 
Thailand. Rather the relationships between rural parents and their geographically dispersed children have changed in ways consistent with the 'modified extended family' perspective common in discussions regarding elderly parents in developed countries. This is undoubtedly the most significant implication of our study, and provides a very different theoretical perspective with which to view the impact of migration, and indeed social change more generally, than the more common modernisation framework that underlies most of the assertions of declining elderly welfare in the third world (Aboderin, 2004).

Although the Thai context differs in numerous respects from that of the US and other Western societies, many similar forces shape family life in an increasingly globalised world. Our research suggests intriguing parallels in how families adapt to these changes. In particular, extended family ties, especially relationships between adult children and their parents, do not simply dissolve because of geographical dispersal. In his original formulation of the 'modified extended family', Litwak (1960) postulated that extended family relations can be maintained over great geographical distances because of modern advances in communication technology. Greater spatial separation precludes neither financial assistance to members elsewhere, nor the maintenance of emotional ties and social exchange. In particular, contact is facilitated by the telephone and better transportation facilities (Smith, 1998). This characterises the situation of many of the parents we interviewed. Recent research on elderly men in Mexico comes to a similar conclusion (De Vos et al., 2004). While there are deserted elderly parents in rural Thailand who have been 'left behind' by children in the cities, they are exceptional. Most rural-based parents and their migrant children are adapting to the increasing need to live apart in ways that maintain family relationships and provide each other with support.

In general, our findings are also consistent with much of the academic literature on rural to urban migration in developing countries that sees benefits to both migrants and household members who remain behind in rural areas. The extent to which migration of adult children can be seen as a conscious strategy of rural parents to either minimise risk or maximise benefits to themselves or the entire family, however, is not clear from our findings.

That said, two important caveats to this conclusion seem appropriate. Firstly, the full impact of migration on rural parents can only be known by the end of the parents' lifetime. Of particular interest are the adaptations during the final stages of life when frailty and health may require daily personal assistance (Litwak and Kulis, 1987). Our research design does not permit this kind of assessment. A second caveat is that the rapid transition to low fertility several decades ago would pose new challenges to maintaining a 'modified extended family' for the next generation of elderly parents and their adult children. While past high fertility and improved mortality ensured that current Thai elders have relatively large numbers of living children, future cohorts entering the elderly age group will have substantially fewer. According to the Survey of Elderly in Thailand, $44 \%$ of persons aged 50-54 in 2002 have only two or fewer children (original tabulations). Moreover, when younger cohorts reach older ages, the large majority will have only two surviving children. Thus the current situation, in which some siblings remain with their rural elderly parents and others migrate, will become increasingly difficult to maintain. This could substantially change the implications of migration for the well-being of the parents, especially when illness or frailty sets in and daily personal assistance is needed.

\section{ACKNOWLEDGMENT}

This research was funded through a grant by the Mellon Foundation to the Population Studies Center, University of Michigan, entitled 'Research and Training in the Demography of Urbanization, Internal Migration, and Urban Life in Developing Countries'. A version of this report was presented at the International Workshop on "The Impacts of Migration on the "Left-Behind" in Asia', 10-11 March 2005 in Hanoi, Vietnam, sponsored by the Asian MetaCentre, National University of Singapore. We are indebted to Jiraporn Kespichayawattana and Suwinee Winwatwanich of the Faculty of Nursing, Chulalongkorn University, who are co-investigators in the project and who participated fully in the collection of the data on which much of this report is based. 


\section{NOTES}

(1) Original tabulations from the 2002 Survey of Elderly in Thailand.

(2) A detailed description of the method and the evaluation of its accuracy is described elsewhere (Knodel and Saengtienchai, 2005).

(3) Five cases were either widowed or divorced and the remainder consisted of currently married couples (although in some one spouse was under age 60 ). For married couples, we talked with the couple jointly if possible.

(4) The principal investigators in the project conducted the interviews and prepared detailed summaries based on tape recordings including selected transcription of the actual interview. Thematic analysis was conducted of the summaries, both in original Thai and in English translation.

(5) Our study design has several important limitations. We can only examine the impact up to the time of the study. Future consequences may well differ as the elderly parents and their adult children move into other stages of life courses. Also our data are from four localities only and may reflect a restricted range of circumstances that condition migration's impact, particularly given the importance of community social networks in stimulating and directing migration, thus increasing the locality specific nature of impacts (Curran and Saguy, 2001; Curran et al., 2003; De Jong, Richter, and Isarabhakdi, 1996; Stark and Bloom, 1985). Nevertheless, while not representative in any rigorous sense, our findings reveal a number of features of the situation in rural Thailand that are likely to be fairly common.

(6) Original tabulations from the Survey of Welfare of the Elderly in Thailand.

\section{REFERENCES}

Aboderin I. 2004. Modernisation and ageing theory revisited: current explanations of recent developing world and historical Western shifts in material family support for older people. Ageing and Society 24: 29-50.

Burholt V. 1999. Testing a behavioural and a developmental model of migration: a reevaluation of migration patterns among the elderly and why older people move. Environment and Planning A 31: 2071-2088.

Cai Q. 2003. Migrant remittances and family ties: a case study in China. International Journal of Population Geography 9: 471-483.

Charasdamrong P. 1992. The misery of those left behind. Bangkok Post 10 May.

Copyright $\odot 2006$ John Wiley \& Sons, Ltd.
Chayovan N, Knodel J. 1997. The Survey of the Welfare of Elderly in Thailand. Institute of Population Studies, Chulalongkorn University: Bangkok.

Choi NG. 1996. Older persons who move: reasons and health consequences. Journal of Applied Gerontology 15: 325-344.

Coles RL. 2001. Elderly narrative reflections on the contradictions in Turkish village family life after migration of adult children. Journal of Aging Studies 15: 383-406.

Curran SR, Garip F, Chung C, Tangchonlatip K. 2003. Migration, cumulative causation and gender: evidence from Thailand. Paper presented at the Conference on African Migration in Comparative Perspective, 4-7 June 2003, Johannesburg.

Curran SR, Saguy AC. 2001. Migration and cultural change: a role for gender and social networks? Journal of International Women's Studies 2(3): 54-77.

Cutchin MP. 2001. Deweyan integration: moving beyond place attachment in elderly migration theory. International Journal of Aging \& Human Development 52: 29-44.

De Jong GF, Richter K, Isarabhakdi P. 1996. Gender, values, and intentions to move in rural Thailand. International Migration Review 30: 748-770.

De Vos S, Solis P, De Oca VM. 2004. Receipt of assistance and extended family residence among elderly men in Mexico. International Journal of Aging $\mathcal{E}$ Human Development 58: 1-27.

Guest P. 1998. Assessing the consequences of internal migration: methodological issues and a case study on Thailand based on longitudinal household survey data. In Migration, Urbanization, and Development: New Directions and Issues, Bilsborrow RE (ed.). United Nations Population Fund (UNFPA): New York; 275-310.

Jamuna D. 1997. Stress dimensions among caregivers of the elderly. Indian Journal of Medical Research 106: 381-388.

Khun R. 2004. Old-age support and changing migration patterns in Bangladesh. University of Colorado Population Aging Center Working Papers 2004-06, Boulder, Colorado.

Knodel J, Saengtienchai C. 1999. Studying living arrangements of the elderly: lessons from a quasi qualitative case study approach in Thailand. Journal of Cross-Cultural Gerontology 14: 197-220.

Knodel J, Saengtienchai C. 2005. Rural Parents with Urban Children: Social and Economic Implications of Migration on the Rural Elderly in Thailand. PSC Research Report 05-474. Population Studies Center: Ann Arbor, MI.

Knodel J, Chayovan N, Siriboon S. 1992a. The impact of fertility decline on familial support for the elderly - an illustration from Thailand. Population and Development Review 18: 79-103.

Popul. Space Place 13, 193-210 (2007) DOI: $10.1002 / p s p$ 
Knodel J, Chayovan N, Siriboon S. 1992b. The familial support system of Thai elderly: an overview. AsiaPacific Population Journal 7: 105-126.

Knodel J, Saengtienchai C, Sittitrai W. 1995. The living arrangements of elderly in Thailand: views of the populace. Journal of Cross-Cultural Gerontology 10: 79-111.

Knodel J, Chayovan N, Graiurapong S, Suraratdecha C. 2000. Ageing in Thailand: an overview of formal and informal support. In Ageing in the Asia-Pacific Regions: Issues and Policies, Phillips D (ed.). Routledge: London; 243-266.

Knodel J, Chayovan N, Mithranon P, Amornsirisomboon P, Arunraksombat S. 2005. Thailand's Older Population: Social and Economic Support as Assessed in 2002. PSC Research Report 05-471. Population Studies Center: Ann Arbor, MI.

Kosberg JI, Garcia JL. 2004. Change in traditional roles for elderly men and women. Journal of the International Institute on Aging 14(3): 3-10.

Litwak E. 1960. Geographic-mobility and extended family cohesion. American Sociological Review 25: 385-394.

Litwak E, Kulis S. 1987. Technology, proximity, and measures of kin support. Journal of Marriage and the Family 49: 649-661.

Lloyd-Sherlock P. 1998. Old age, migration, and poverty in the shantytowns of Sao Paulo, Brazil. Journal of Developing Areas 32: 491-514.

Ministry of Public Health 2004. ICPD at 10: Progress and Challenges in Implementing the PoA. Ministry of Public Health: Bangkok.

Osaki K. 1999. Economic interactions of migrants in their households of origin: are women more reliable supporters? Asian and Pacific Migration Journal 84: 447-471.

Richter K. 1996. Living separately as a child-care strategy: implications for women's work and family in urban Thailand. Journal of Marriage and the Family 58: 327-339.

Sando RA. 1986. Doing the work of two generations: the impact of out-migration on the elderly in rural Taiwan. Journal of Cross-Cultural Gerontology 1: 163-175.

Sen, Kasturi. 1994. Ageing: Debates on Demographic Transition and Social Policy. London, Zed Books Ltd.

Silverstein M, Angelelli JJ. 1998. Older parents' expectations of moving closer to their children. Journals of Gerontology Series B - Psychological Sciences and Social Sciences 53: S153-S163.

Smith GC. 1998. Residential separation and patterns of interaction between elderly parents and their adult children. Progress in Human Geography 22: 368-384.

Sorensen C. 1986. Migration, the family, and the care of the aged in rural Korea: an investigation of a village in the Yongso region of Kangwon Province 1918-1983. Journal of Cross-Cultural Gerontology 1: 139-161.

Stark O, Bloom DE. 1985. The new economics of labor migration. American Economic Review 75: 173-178.

Stark O, Lucas REB. 1988. Migration, remittances, and the family. Economic Development and Cultural Change 36: 465-481.

United Nations. 2002. Report of the Second World Assembly on Ageing: Madrid, 8-12 April 2002. United Nations: New York.

United Nations. 2005. World Population Prospects: The 2004 Revision. Volume I: Comprehensive Tables. United Nations: New York.

United Nations Population Fund. 2002. Population Ageing and Development: Social, Health and Gender Issues. UNFPA, Population and Development Strategies: New York.

VanWey L. 2004. Altruistic and contractual remittances between male and female migrants and households in rural Thailand. Demography 41: 739-756. 